\title{
A CIRCULAR ECONOMY APPROACH TO THE DESIGN OF A WATER NETWORK TARGETING THE USE OF REGENERATED WATER
}

\author{
Ana Somoza-Tornos*, Manuel Rives-Jiménez, Antonio Espuña, Moisès Graells \\ Chemical Engineering Department, Universitat Politècnica de Catalunya, EEBE, \\ C/ Eduard Maristany 16, 08019 Barcelona, Spain
}

\begin{abstract}
Increasing water demand by the process and allied industries coupled with global water stress and scarcity have underlined the importance of water as a crucial resource and increased the need for widespread adoption of water reuse and recycle. Early research based on water-pinch analysis addressed the use of systematic methods to identify the most promising opportunities for water reuse within a process plant. More recent work has addressed similar concepts in the framework of industrial symbiosis and EcoIndustrial Parks (EIP) under the assumption of the leadership of an EIP authority. However, many wastewater plants continue processing wastewater to condition water for disposal, which means meeting the limits given by given regulations at a minimum cost. These wastewater plants may play a role in a growing market of regenerated water in which an increasing number of businesses and public services demanding water with different quality specifications. Hence, this work is presenting an MINLP model aimed at exploiting the flexibility of a wastewater treatment plant and maximizing its profit within this market. Results and discussion are provided in regard of a case study based on a wastewater treatment plant nearby Barcelona.
\end{abstract}

Keywords

Circular Economy, Water Management, Optimization.

\section{Introduction}

Rising scarcity in fresh water resources coupled with an unrelenting increase on the water demand have pointed out the need of water reuse and recycle (United Nations Environment Programme, 2008). This is in accordance with the research requirements in order to reduce the consumption of natural resources (Ahmetović, 2015)

The need to reintroduce used water in the water cycle once conveniently regenerated or conditioned to specific customer needs requires a systematic approach in order to close water loops in the most efficient way.

In this light, water pinch methodology has been one of the most widely used approaches to systematize water treatment and reuse (Foo, 2009). It is still growing with recent developments (Klemeš et al. 2018).
In the last years, formulations derived from the waterpinch method have been extended to consider industrial symbiosis approaches, where water is not only shared between different processes within a single area, but also between different industries and sites.

The focus of the recent research has been to extend these ideas to the design of water networks of eco-industrial parks (EIP), which involve not only multiple processes, water sources and sinks, but also multiple stakeholders.

In this regard, a pioneering work by Aviso et al. (2010) proposed a bi-level fuzzy optimization approach aimed at maximizing water exchange within eco-industrial parks, taking into account the regulations being implemented in the park. Hence, this kind of approach is centered in an EIP

\footnotetext{
* To whom all correspondence should be addressed
} 
authority at the upper decision-making level. Tenant companies are expected to follow the conditions set by the EIP authority in pursuit of a common good.

Boix et al. (2011) developed a generic model based on a multiobjective optimization approach for the design of a water supply system for an eco-industrial park, and showed that the best configuration could be efficiently identified by simultaneously minimizing the fresh water flow rate, the regenerated water flow rate and the number of connections within the eco-industrial park; furthermore, the same authors expanded this work to assess the flexibility of a water-network design (Montastruc et al., 2016), and DeLeón Almaraz et al. (2016) extended these ideas in order to integrate energy exchanges within a EIP, proposing a new strategy for the design of Water Allocation and Heat Exchange Networks for multi-contaminant problems. Tiu and Cruz (2017) employed conflicting economic and environmental indicators in a weighted MILP model aimed at solving the trade-off between the diverse impacts produced by an EIP.

However, these industry-centered approaches do not take into account other elements which also may help to improve the efficiency of the overall water cycle, such as satisfying ecological requirements, managing agricultural irrigation or treating urban water. Furthermore, the model assumes the presence of an EIP authority, which does not match the situation found in many existing wastewater treatment plants, that may play a significant role in a future market of conditioned water for social and industrial needs.

The approach presented in this work is centered on the point of view of the wastewater treatment business that seeks to minimize costs considering scenarios in which options additional to disposal exist. On one hand, the common social or administrative deal needs to be met at the minimum cost (bringing wastewater to disposal conditions); but, on the other hand, added value can be produced at a higher cost, since conditioned water can be sold to new customers willing to pay for water if it meets their quality specifications.

The approach here presented extends the strategy developed in a previous work (Somoza-Tornos et al., 2018) aimed at the maximization of industrial symbiosis opportunities. The model considers a transformation company seeking its own profit by processing wastewater from a set of available supplying processes and providing it as a raw material to a different set of water demanding processes.

\section{Problem Statement}

The design problem addressed in this contribution has as objective to determine the configuration of a generalized water network, including water sources and sinks, water users, water regeneration units, wastewater treatment units, and recycling/reusing options. The problem can be posed as follows:

Given are:
- A set of water inlets $h$ with a known composition of contaminants $j$. Some of these inlets are wastewater streams, which might also be the aggregated result of collecting wastewater from different sources.

- A set of available wastewater treatment units $i$ with different elimination technologies that are managed through the definition of a set if operating modes $r$. Each plant and operating mode has an associated cost.

- A set of water demands $k$ from potential customers. These demands will generate an associated profit when the purity and flowrate constraints fixed by the customers are satisfied, and may also include ecological related demands (e.g.: aquifer direct/indirect injection), industrial/services requirements, agricultural requirements, etc. Other environmental constraints should be also considered, like maximum pollutants loads and/or concentration in the water sinks, etc.).

The decisions to be made include:

- Distribution of wastewater into treatment units.

- All the flowrates and compositions required to characterize the best way of satisfying the requirements from the different customers.

Hence, the optimal treatment and distribution network has to be determined.

A generic superstructure used to model the problem is represented in Figure 1.

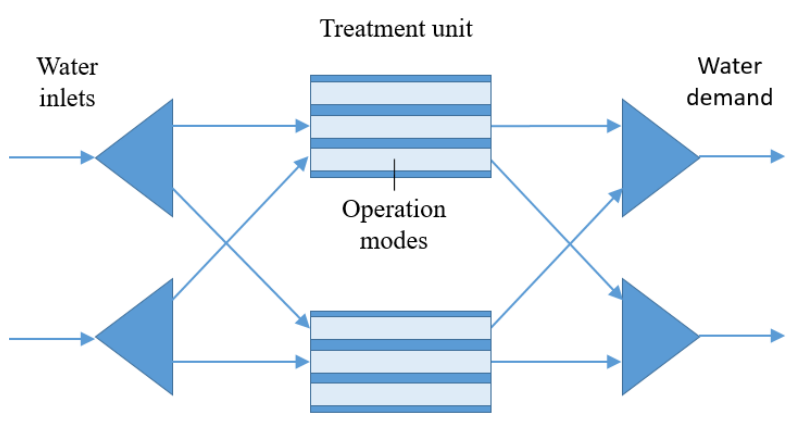

Figure 1. Superstructure for two inlets, two treatment units with three operation modes each and two water demand streams.

\section{Mathematical Formulation}

The problem is addressed through the formulation of a Mixed Integer Non-Linear Programming model in which continuous variables represent flowrates and concentrations and binary variables are associated to the states and decisions of the system.

\section{Water inlet}

Equation (1) defines the repartition of the global inlet to the wastewater treatment plant $\left(\operatorname{Qin}_{h}\right)$ into the different lines $\left(Q t u_{i}\right)$. This division is done through continuous variable $X_{i}$ with a range of $[0,1]$, which must sum up 1 to ensure that all water is treated (Eq. (2)). 
$Q t u_{i}=X_{i} \cdot \sum_{h} \operatorname{Qin}_{h} \quad \forall i$

$\sum_{i} X_{i}=1$

\section{Treatment units}

Binary variable $b_{r}$ represents the operation mode $r$ that is active in treatment unit $i$. Equation (3) calculates the water processed under the operation mode. Each line can only operate under a single mode at the same time, thus Eq. (4) is defined.

$$
\begin{array}{cc}
Q o m_{r}=b_{r} \cdot Q t u_{i} & \forall r \mid R_{\text {ir }}=1 \\
\sum_{r}\left(b_{r} \cdot R_{\text {ir }}\right)=1 & \forall i
\end{array}
$$

Equation (5) represents the calculation of the concentration of treated water $\operatorname{Com}_{r j}$ as a function of the active operation mode, the removal ratio $\rho_{i r}$ and the inlet concentration $\operatorname{Cin}_{h j}$. The binary variable $b_{r}$ represents the operation mode $r$ that is active in treatment unit $i$. Hence, global concentration of the treatment unit $C t u_{i j}$ can be calculated as in Eq. (6).

$\operatorname{Com}_{r j}=b_{r} \cdot\left(1-\rho_{r j}\right) \cdot \operatorname{Cin}_{h j}$

$\forall r j$

$\mathrm{Ctu}_{i j}=\sum_{r}\left(\mathrm{Com}_{r j} \cdot R_{\text {ir }}\right)$

In addition, each line and operation mode can only be active when inlet requirements, defined in Eq. (7), are satisfied.

$\underline{\operatorname{MinCin}}_{r j} \leq \operatorname{Cin}_{h j} \cdot b_{r} \leq \overline{\operatorname{MaxC} i n_{r j}}$

To ensure that the removal process has been successful, the outlet concentration has to fulfill the limits in Eq. (8).

$\underline{\operatorname{MinCom}}_{r j} \leq \operatorname{Com}_{r j} \leq \overline{\operatorname{MaxCom}}_{r j}$

The removal ratio is defined as a variable to reflect changes in operation conditions that may lead to different efficiencies, which will be assessed afterward when the costs of the treatment unit are calculated. Equation (9) expresses the range in which efficiency can move.

$\underline{\operatorname{Min} \rho_{r j}} \leq \rho_{r j} \cdot b_{r} \leq \overline{\operatorname{Max} \rho_{r J}}$

\section{Demand satisfaction}

Qout $_{k}$ is a continuous variable denoting the flowrate sent to satisfy demand $k$, and is calculated in Eq. (10) through the factor $Y_{i k}$ with range [0,1] (Eq. (11)). Equation (12) expresses the limits to be satisfies by Qout $_{k}$.

$$
\begin{array}{lr}
\text { out }_{k}=\sum_{i}\left(Y_{i k} \cdot Q t u_{i}\right) & \forall k \\
\sum_{k} Y_{i k}=1 & \forall i
\end{array}
$$

MinQout $_{k} \leq$ Qout $_{k} \leq \overline{\text { MaxQout }_{k}}$

$\forall k$

Equations $(13,14)$ are the analogous definition and limit satisfaction constraint for the outlet concentration Cout $_{k j}$.

$\operatorname{Cout}_{k j}=\sum_{i}\left(Y_{i k} \cdot \operatorname{Cin}_{i j} \cdot \operatorname{Qin}_{i}\right) / \sum_{i}\left(Y_{i k} \cdot Q_{i n}\right) \forall k j$

MinCout $_{k j} \leq$ Cout $_{k j} \leq \overline{\text { MaxCout }_{k J}}$

$a_{k}$ is defined by Eqs. $(15,16)$ as a binary variable that takes a value of 1 if $Q$ out $t_{k}$ is greater than the demand $D_{k}$.

$\left(\right.$ Qout $\left._{k}-D_{k}\right) \geq M \cdot\left(1-a_{k}\right) \quad \forall k$

$\left(D_{k}-\right.$ Qout $\left._{k}\right) \leq M \cdot a_{k}$

$\forall k$

\section{Objective function}

The objective function to be maximized is the economic balance represented in Eq. (17). It includes the transformation cost as a function of the efficiency, the penalties for not satisfying the demand and the income from selling the regenerated water.

$$
\begin{aligned}
& \text { OF }=\sum_{k}\left(a _ { k } \cdot \left(\text { Binf } _ { k } \cdot \text { Qout } _ { k } - \text { Pinf } _ { k } \cdot \left(D_{k}-\right.\right.\right. \\
& \text { Qout } \left.\left.\left._{k}\right)\right)-\left(1-a_{k}\right) \cdot\left(\text { Psup }_{k} \cdot\left(\text { Qout }_{k}-D_{k}\right)\right)\right)- \\
& \sum_{k}\left(\left(\alpha_{r} \cdot \sum_{j}\left(\frac{\rho_{r j}}{\operatorname{card}(j)}\right)+\beta_{r}\right) \cdot \text { Qom }_{r}\right)
\end{aligned}
$$

\section{Problem formulation}

The resulting model for the water network design can be posed as follows:

Model $\max [\mathrm{OF}]$

$$
\text { s.t. Eqs. (1-16) }
$$

\section{Case Study}

The model has been tested on a case study based on a real water network in the outskirts of Barcelona.

The system should manage an aggregated wastewater stream of $55000 \mathrm{~m}^{3} /$ day.

The available treatment lines include:

- A Membrane Bioreactor (MBR) with a capacity of $25000 \mathrm{~m}^{3} /$ day.

- An Integrated Fixed-Film Activated Sludge (IFAS) with a capacity of $25000 \mathrm{~m}^{3} /$ day.

- A Traditional Wastewater Treatment Line (TWT) with a capacity of $60000 \mathrm{~m}^{3} /$ day.

All of them include the possibility of carrying out nutrient removal. This possibility is characterized by defining two operation modes, depending if the nutrient removal is or is not active.

The following key parameters must be traced during wastewater treatment: Suspended Solids (SS), Biochemical Oxygen Demand (BOD), Chemical Oxygen Demand 
(COD), Total Nitrogen $(\mathrm{N})$ and Phosphorous (P). Each line has a defined efficiency range for the elimination of each one of these contaminants according to its operating mode.

Ten potential water customers have been also identified, with their respective flowrate and purity constraints. Conventional customers include industries and service clusters. There is one ecological related customer associated to the convenience to cover direct water injection to an aquifer. In addition, and in order to face water excess after treatment, a customer with a high demand and zero profit specifications is defined (final water disposal).

\section{Results and Discussion}

The proposed model, featuring 337 equations, 195 continuous variables and 16 binary variables, was coded in GAMS 24.4.6 and solved with BARON, obtaining a solution with $4 \mathrm{k} € /$ day savings respect of the current plant operation.

Figure 2 compares the contaminant concentration at the wastewater inlet with the maximum removal capacity of each line. This concentration is compared to the legal limit for water disposal into the sea, to check the performance of the system.

As observed, both the IFAS/SF and MBR units allow meeting the legal requirements for seaside disposal, yet the MBR system can eliminate contaminants well beyond the minimum standards (e.g. down to 30 COD compared to the 125 required by legislation), therefore helping to meet the more demanding customer requirements.
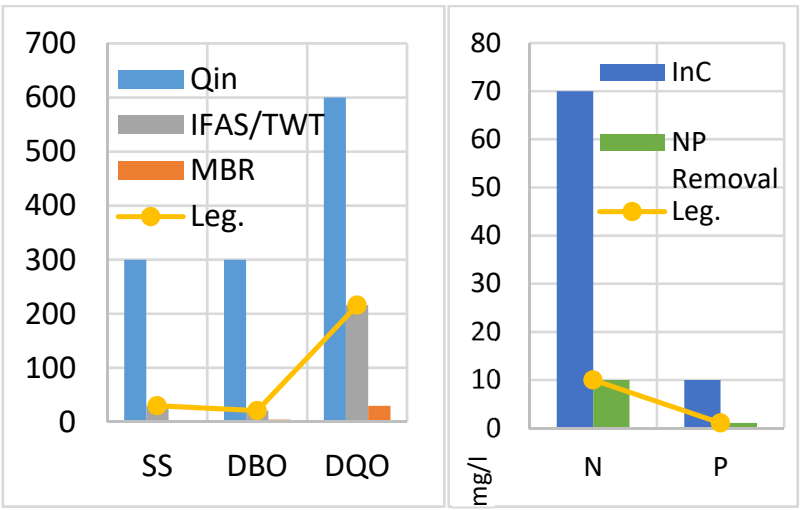

Figure 2. Inlet and performance of the contaminant removal of the three lines and of the nutrient removal system.

The distribution of the wastewater inlet into the three available lines is depicted in Figure 3. MBR is almost used at their full capacity, while IFAS is working at a $48 \%$ of its nominal capacity and conventional wastewater treatment would only be working at a $30 \%$ of its nominal capacity.

There are different factors which shape this decision. On the one hand, the MBR is required to meet the most strict water specifications since it is the system showing the highest contaminant removal. On the other hand, IFAS and TWT show similar performances in regard of removal ratio, and are used under different operation modes. While IFAS performs nutrient removal, TWT does not, offering more flexibility to the process. In addition, the former is the preferred option to produce water with a higher quality since it allows taking advantage of its strategic location, attaining significant saving in transportation costs compared to the conventional system, which is geographically displaced.

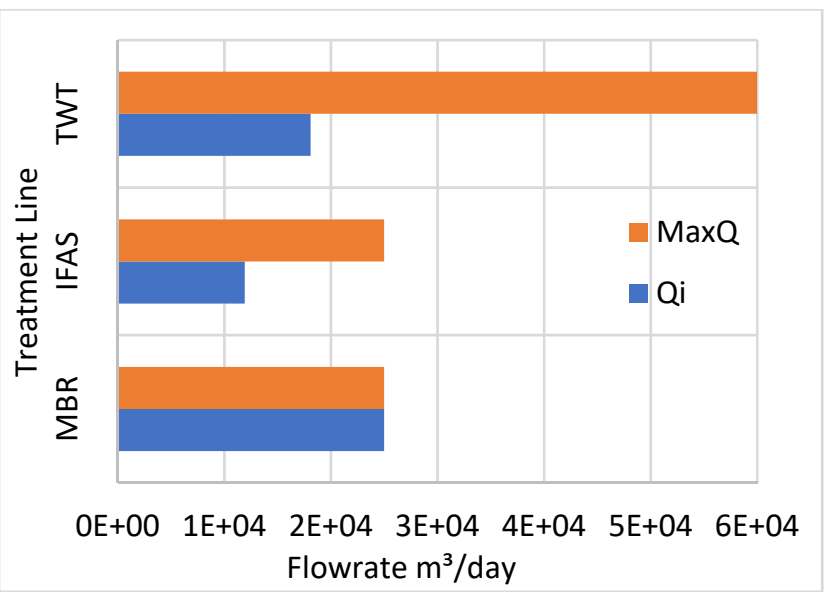

Figure 3. Wastewater inlet to each line compared to its maximum capacity of the line.

The contaminant concentrations of the final water streams, compared to the corresponding customer requirements are shown in Figure 4. All contaminants are removed inside the legal limits.

Turning our attention to customers, we find that the most demanding requirements are those of $\mathrm{K} 4$ and $\mathrm{K} 5$ and, as a result, contaminants are not removed between the allowable limits (i.e. Eq. (14) is active for $k=\mathrm{K} 4$ and $\mathrm{K} 5$ in the optimal solution), and SS acts as bottleneck.

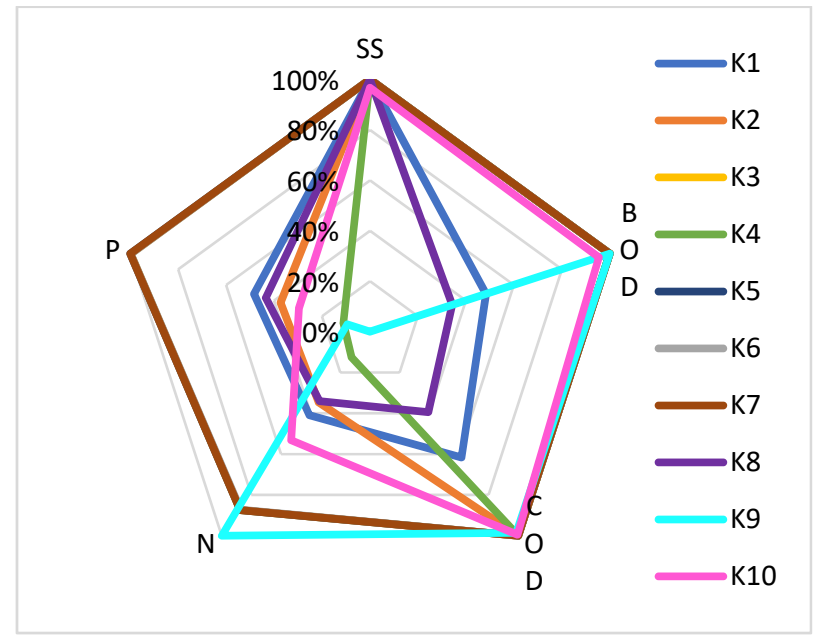

Figure 4. Contaminant concentration expressed as a percentage of the allowable limit for each satisfied stream.

Figure 5 illustrates the final network design. The inlet is divided into the three lines and the outlets are mixed and distributed to satisfy the demand of regenerated water from the different customers. 
As MBR provides the water of highest quality, it is used to meet the requirements of the most demanding customers. Mixtures of water from MBR and IFAS or TWT satisfy clients with medium requests, in order to decrease the treatment cost. Conversely, K10 water specifications are lower, so it is satisfied with water from IFAS and TWT.

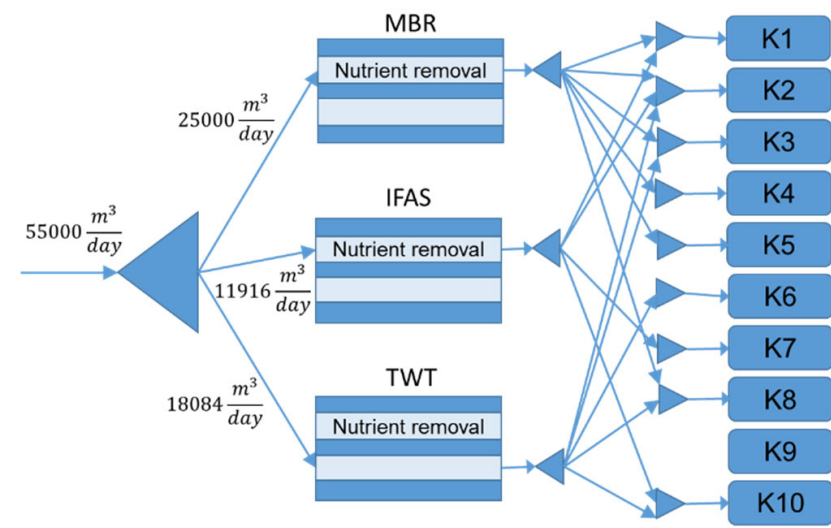

Figure 5. Resulting network design for the case study.

In order to satisfy more of the customers, new water sources might be introduced into the system, and some investments should be done to update or acquire new equipment, allowing the satisfaction of other customers demanding more purity.

\section{Conclusions}

In this contribution, we have presented an optimization model able to identify the most promising alternatives for the design of a reconditioned water network. This has been done from a wide scope where different water sources (from urban sewage water to industrial effluents) and consumers (from farmlands irrigation to service facilities) are considered.

Results show the capabilities of the model to systematically provide solutions to the design problem (e.g. the calculation of the optimal combination of water from different treatment lines and technologies to solve the tradeoff between operation cost reduction and purity satisfaction).

The proposed approach reflects a change of paradigm in the role of wastewater treatment plants, from passively receiving wastewater and reconditioning it for seaside disposal to an active attitude towards profit maximization. This repositioning will add extra pressure to this kind of facilities, which were designed to meet the water discharge limits established by legislation at a minimum cost.

In this light, results suggest that existing wastewater treatment technologies can be a good starting point to create a much environmentally needed regenerated water network.

However, if the recycling of water is to be pressed to its maximum capacity, which is highly probable due to the expected demand increase united to resources shortage, there is a need of investing on higher efficiency technologies, such as MBR. In parallel, it is crucial to work on a complete inventory, independently of its source, of the water flows in different areas, to design treatment plants according to it.

Future work will also address the analysis of the role of recalcitrant contaminants, together with the incorporation of the tertiary treatment units required to their efficient elimination.

\section{Nomenclature}

Sets

$$
\begin{aligned}
i & =\text { Treatment lines } \\
h & =\text { Inlet wastewater stream } \\
j & =\text { Contaminant } \\
k & =\text { Demand stream } \\
r & =\text { Operation mode } \\
R_{\text {ir }} & =\text { Operation mode } r \text { that exists in treatment }
\end{aligned}
$$

Parameters

$$
\begin{aligned}
\operatorname{Qin}_{h}= & \text { Wastewater inlet flowrate } h\left[\frac{\mathrm{m}^{3}}{\text { day }}\right] \\
\operatorname{Cin}_{h j}= & \begin{array}{l}
\text { Concentration of contaminant } j \text { at inlet } \\
\text { stream } h[p p m]
\end{array}
\end{aligned}
$$

$\underline{\text { MinCin }}_{r j}=$ Minimum concentration of contaminant $j$ at the inlet of operation mode $r$ [ppm]

$\overline{\overline{M a x C \imath n_{r \jmath}}}=$ Maximum concentration of contaminant $j$ at the inlet of operation mode $r$ [ppm]

MinCom $_{r j}=$ Minimum concentration of contaminant $j$ at the outlet of operation mode $r$ [ppm]

$\overline{\operatorname{MaxCom}_{r j}}=$ Maximum concentration of contaminant $j$ at the outlet of operation mode $r$ [ppm]

$\operatorname{Min} \rho_{r j}=$ Minimum efficiency of contaminant $j$ removal at operation mode $r$ [0-1]

$\overline{\overline{\operatorname{Max} \rho_{r j}}}=$ Maximum efficiency of contaminant $j$ removal at operation mode $r$ [0-1]

$$
M=\operatorname{Big} \mathrm{M}\left[\frac{m^{3}}{d a y}\right]
$$

$\overline{\overline{\operatorname{MaxCom}_{r j}}}=$ Maximum concentration of contaminant $j$ at the outlet of operation mode $r$ [ppm]

$\operatorname{Binf}_{k}=$ Profit for satisfying the demand of stream $k\left[\frac{€}{m^{3}}\right]$

$\operatorname{Pinf}_{k}=$ Penalty for not satisfying the demand of stream $k\left[\frac{€}{m^{3}}\right]$ 
Psup $_{k}=$ Penalty for exceeding the demand of stream $k\left[\frac{€}{m^{3}}\right]$

$\alpha_{r}=$ Cost coefficient for operation mode $r$ [€]

$\beta_{r}=$ Cost coefficient for operation mode $r$ [€]

Variables

- Positive

$$
\begin{aligned}
& Q t u_{i}=\quad \text { Flowrate at treatment unit } i\left[\frac{m^{3}}{d a y}\right] \\
& X_{h i}=\text { Fraction of inlet } h \text { sent to treatment unit } i
\end{aligned}
$$

- Binary

$$
\begin{aligned}
& a_{k}=1 \text { if } \text { Qout }_{k} \leq D_{k}, 0 \text { otherwise } \\
& b_{r}=1 \text { if operation mode } r \text { is active, } 0 \text { otherwise }
\end{aligned}
$$

network design. Journal of Environmental Management, 92, pp. 1802-1810.

De-León Almaraz, S., Boix, M., Montastruc, L., Azzaro-Pantel, C., Liao, Z., Domenech, S. (2016). Design of a water allocation and energy networkfor multi-contaminant problems usingmulti-objective optimization. Process Safety and Environmental Protection, 103, pp. 348364.

Foo, D. C. Y. (2009). State-of-the-Art Review of Pinch Analysis Techniques for Water Network Synthesis. Industrial \& Engineering Chemistry Research, 48 (11), pp. 5125-5159.

Klemeš, J., Varbanov, P. S., Walmsley, T. G., Jia, X. (2018). New directions in the implementation of Pinch Methodology (PM). Renewable and Sustainable Energy Reviews, 98, pp. 439-468.

Montastruc, L., Boix, M., Pibouleau, L., Azzaro-PanteL, C., Domenech, S. (2013). On the flexibility of an ecoindustrial park (EIP) for managing industrial water. Journal of Cleaner Production, 43, pp. 1-11.

Ramos, M. A., Boix, M., Aussel, D., Montastruc, L., Domenech, S. (2016). Water integration in eco-industrial parks using a multi-leader-follower approach. Computers \& Chemical Engineering, 87, pp. 190-207.

Somoza-Tornos, A., Graells, M., Espuña, A. (2018). Evaluating the effect of separation and reaction systems in industrial symbiosis. Computer Aided Chemical Engineering, 43, pp. 749-754.

Tiu, B. T. C., Cruz, D. E.. (2017). An MILP model for optimizing water exchanges in eco-industrial parks considering water quality. Resources, Conservation and Recycling, 119, pp. 89-96.

United Nations Environment Programme. Vital Water Graphics: an Overview of the State of the World's Fresh and Marine Waters, $2^{\text {nd }}$ ed.; United Nations Environment Programme: Nairobi, Kenya, 2008.

\section{Acknowledgments}

Financial support received from the Spanish "Ministerio de Economía, Industria y Competitividad" and the European Regional Development Fund, both funding the research Project AIMS (DPI2017-87435-R) is fully acknowledged.

Ana Somoza-Tornos thankfully acknowledges financial support received from the Spanish "Ministerio de Educación, Cultura y Deporte" (Ayuda para la Formación de Profesorado Universitario - FPU15/02932).

\section{References}

Ahmetović, E., Ibrić, N., Kravanja, Z., Grossmann, I. E. (2015). Water and energy integration: A comprehensive literature review of non-isothermal water network synthesis. Computers \& Chemical Engineering, 82, pp.144-171.

Aviso, K. B., Tan, R. R., Culaba, A. B., Cruz, J. B. Jr. (2010). Bilevel fuzzy optimization approach for water exchange in eco-industrial parks. Process Safety and Environmental Protection, 88, pp. 31-40.

Boix, M., Montastruc, L., Pibouleau, L., Azzaro-PanteL, C., Domenech, S., (2011). A multiobjective optimization framework for multicontaminant industrial water 